\title{
NEWS
}

\section{Argentina smooths the path for returnees}

In Central and South American countries fearing brain drain, government-sponsored efforts to attract researchers home from overseas typically offer lucrative compensation packages. But many scientists have an additional priority - their family members, who are often of different nationalities. In the case of Argentina, immigration procedures for non-Argentinian partners and children often take months or even years to complete. An agreement struck last month as part of the country's repatriation programme for scientists now promises to smooth the transition.

On 11 June, Argentina's Ministry of Science, Technology and Productive Innovation and the National Immigration Department signed an agreement to speed up immigration procedures for scientists who want to return to Argentina with their foreign families. The agreement means that applicants need present only part of the required paperwork and will receive residence permits within a couple of months, estimates science minister Lino Barañao. The agreement also applies to foreign researchers who wish to work in Argentina, either temporarily or permanently.

According to Barañao, the agreement

will "facilitate a process which is often very

cumbersome". The aim is to attract both

Argentinian and foreign

researchers from abroad

who can "bring new points

of view or ideas, which in

turn trigger new research

possibilities", says Vicente

Macagno, vice-president

of scientific affairs at the

National Scientific and

Technical Research Council,

based in Buenos Aires.

The migration agreement

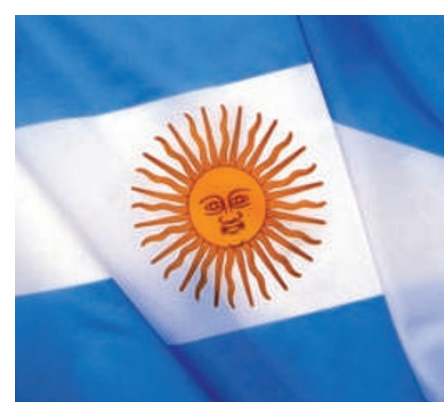

the RAICES (Spanish for 'roots') programme, started in 2003 by Argentina's science ministry to encourage the repatriation of Argentinian scientists. Since its implementation, RAICES has helped 768 Argentinian scientists return home by providing subsidies that cover the costs of moving, private or state grants to cover salary until a job is secured, and funds for research. In 2004, there were around 59,000 researchers in Argentina; in 2008 that number rose to should help, says biologist Alejandro Nadra, who, after earning his PhD in 2005, went to Spain to find work. He returned to Argentina in June 2009 with his daughter and wife, also a researcher. They are Argentinian, which made the move relatively smooth. But Nadra sees great value in mitigating delays for future colleagues.

The family agreement is an extension of more than 79,000 , with $81 \%$ of them in state institutions.

Government science funding rose from $0.23 \%$ of gross domestic product in 2002 to $0.42 \%$ in 2010 . According to Barañao, many investigators have chosen to return because of the increasingly "important role" of science and technology in Argentina.

Ana Belluscio

\section{PROSPECTS}

\section{Finding a 'real' job}

\section{'Alternative' careers may be commonplace, but that doesn't mitigate a sense of failure, says Katherine Sixt.}

I was just starting high school when I heard my grandfather berating my older cousin about his higher-education choices. "Look in the newspaper," he said. "Do you see any jobs in that profession?" Now, as a postdoc facing the search for a 'real' job, I realize that I might have benefited from a refresher in the economics of supply and demand when first considering my career.

Scientists excel at following protocols. Most have adhered to the same career path: getting good grades in high school and college, getting good grades and publishing papers in graduate school, and publishing more papers as a postdoc. The assumption, especially in the United States, is that this will culminate in a tenure-track faculty position at a good university, followed by tenure and, eventually, emeritus status. Few talented, aspiring scientists detour from this trajectory at an early stage, because most find that good grades are easy to achieve and that there are ample predoctoral and postdoctoral positions. But now, as I confront the academic job bottleneck, I finally have to admit that there are not enough faculty positions for everyone.

These notions are not the musings of a jaded postdoc. I wholeheartedly enjoy the bench and thrive on Socratic discussions with my colleagues and superiors, resolving our different views through rational discourse. But today's academic job market is not encouraging for those intent on a faculty position. According to the US National Science Board's report Science and Engineering Indicators 2010, 56\% more science and engineering doctorates were awarded by US institutions in 2007 than in 1993. The number of postdocs grew by 44\% between 1993 and 2006. The number of tenured and tenure-track faculty positions increased by only $10 \%$ in the same period, and the number of non-tenure-track academic positions increased by $51 \%$.

I see a job market that's changing dramatically for those with doctorates in science. 'Alternative' careers are increasingly becoming the norm. Sometimes, I feel that all roads are leading me away from the bench. The job-market statistics alone are overwhelming, but my lab data also never flow as quickly as I would like. Furthermore, I wonder whether I can handle the pressure of continually producing positive results - I find that working hard does not always yield valuable scientific conclusions. And I've watched more-experienced colleagues with novel findings have their manuscripts rejected time and again. I wonder whether I should satisfy my love of discovery in a different way.

Still, I feel as though I have to sneak off to careers seminars where scientists describe their non-traditional paths. Thoughts of alternative career choices are still dirty secrets for some. Despite many science PhD graduates becoming patent attorneys, science writers or consultants, I'm embarrassed. I have to cajole myself into reasoning that considering other options does not make me a failure but rather a pragmatist. I can't pretend that the past 12 years of schooling and research will lead to the labhead position that I dreamed about in highschool chemistry class.

As a nod to my grandfather, I take an hour away from those irreproducible results. Forgoing newsprint for my laptop, I type 'biomedical PhD jobs' into Google, in the hope of finding that 'real' job.

Katherine Sixt keeps a Postdoc Journal for Naturejobs and is a postdoc in the Laboratory of Cellular and Molecular Biology at the National Cancer Institute in Bethesda, Maryland. 